\title{
Exercise-based cardiac rehabilitation in patients with chronic heart failure: a Dutch practice guideline
}

\author{
R. J. Achttien • J. B. Staal • S. van der Voort • H. M. Kemps • \\ H. Koers • M. W. A. Jongert • E. J. M. Hendriks • \\ on behalf of the Practice Recommendations Development Group
}

Published online: 10 December 2014

(C) The Author(s) 2014. This article is published with open access at Springerlink.com

\begin{abstract}
Rationale To improve the quality of exercise-based cardiac rehabilitation $(\mathrm{CR})$ in patients with chronic heart failure (CHF) a practice guideline from the Dutch Royal Society for Physiotherapy (KNGF) has been developed.

Guideline development A systematic literature search was performed to formulate conclusions on the efficacy of exercise-based intervention during all $\mathrm{CR}$ phases in patients with CHF. Evidence was graded (1-4) according the Dutch evidence-based guideline development criteria.

Clinical and research recommendations Recommendations for exercise-based $\mathrm{CR}$ were formulated covering the following topics: mobilisation and treatment of pulmonary symptoms (if necessary) during the clinical phase, aerobic exercise, strength training (inspiratory muscle
\end{abstract}

R. J. Achttien $(\bowtie) \cdot$ J. B. Staal • E. J. M. Hendriks

Scientific Institute for Quality of Healthcare, Radboud University

Nijmegen Medical Centre, Geert Grooteplein 21 6500, PO Box

9101, Nijmegen, HB, the Netherlands

e-mail: retze.achttien@gmail.com

S. van der Voort

Rehabilitation Department Tergooiziekenhuizen, Zonnestraal,

Hilversum, the Netherlands

H. M. Kemps

Department of Cardiology, Maxima Medical Center, Veldhoven; Department of Medical Informatics, Amsterdam Academic Medical Center, University of Amsterdam, Amsterdam, the Netherlands

H. Koers

Hart op Koers, Gouda, the Netherlands

\section{W. A. Jongert}

Dutch Institute of Allied Health Care, Amersfoort, the Netherlands,

The Hague University of Applied Sciences, The Hague, the

Netherlands training and peripheral muscle training) and relaxation therapy during the outpatient $\mathrm{CR}$ phase, and adoption and monitoring training after outpatient CR.

Applicability and implementation issues This guideline provides the physiotherapist with an evidence-based instrument to assist in clinical decision-making regarding patients with CHF. The implementation of the guideline in clinical practice needs further evaluation.

Conclusion This guideline outlines best practice standards for physiotherapists concerning exercise-based CR in CHF patients. Research is needed on strategies to improve monitoring and follow-up of the maintenance of a physical active lifestyle after supervised CR.

Keywords Chronic heart failure · Exercise-based .

Guideline $\cdot$ Clinical practice

\section{Rationale}

Chronic heart failure (CHF) is defined as 'a complex of signs and symptoms associated with a structural or functional abnormality of the heart'. [1] CHF involves peripheral and central changes, which are functional (as a compensation mechanism) in the short term, but have adverse consequences in the long term, resulting in reduced exercise capacity. The most frequent causes of CHF are hypertension and coronary artery disease; less frequent causes include heart valve diseases, arrhythmias and viral infections. The prevalence and incidence of CHF increases with age, and has an adverse overall prognosis with a 5-year mortality rate of $45 \%$. In 2012, 4136 women and 2625 men died as a consequence of CHF in the Netherlands [2].

Multidisciplinary cardiac rehabilitation (CR) reduces mortality and early hospital readmission, progressive 
deterioration of $\mathrm{CHF}$ and prevents recurrence of cardiac events. [3, 4] Exercise training, usually conducted by physiotherapists, constitutes an important part of CR aiming to improve exercise capacity and quality of life (QoL) both in the short and long term. The mechanisms underlying these beneficial effects involve improvement of muscle perfusion, muscle metabolism, ventilatory efficiency, neurohormonal regulation and cardiac function [4-6].

The exact content of exercise-based CR programs in CHF patients in the Netherlands is not well established. Within Dutch CR centres, there is considerable variation in the methods for determination of exercise intensity training, training intensity and volume. [7] A possible explanation is that guidelines and position statements lack clear practical guidance for physiotherapists. [8-14] Therefore, a clinical practice guideline on exercise-based CR was developed by the Dutch Royal Society for Physiotherapy (KNGF), describing optimal exercise-based $\mathrm{CR}$, including assessment, treatment and evaluation in CHF patients. This clinical practical guideline and the guideline for exercise-based CR in patients with coronary artery disease [15] can be considered as a supplement to the Dutch Multidisciplinary Guideline for CR [9].

\section{Guideline development process}

This guideline has been systematically developed according to the method of Physiotherapy Development in the Netherlands, [16] which is in line with international methods of guideline development [17].

A computerised literature search was undertaken in the Cochrane library, Medline, PEDro-database, Cinahl and relevant available national and international guidelines of $\mathrm{CR}$, [8-14, 18] using the following key words (in Dutch and English): heart disease, chronic heart failure, systolic heart failure, congestive heart failure, treatment outcome, diagnosis, exercise, and physiotherapy.

Recommendations for exercise-based CR were, if they existed, based on systematic reviews or meta-analyses, and if available completed with more recent randomised-controlled trials (RCTs) and otherwise based on RCTs only. Methodological quality of RCTs was scored using the physiotherapy evidence database (PEDro) scale. [19] Only studies with a score of more than 5 out of 10 points were included. If there was insufficient scientific evidence, recommendations were based on consensus within the guideline development group (GDG).
The level of evidence was categorised on the basis of Dutch national agreements on evidence grading for guideline development (EBRO/CBO) (Table 1).

\section{Comments, modification and financing}

The guideline is written by the GDG, consisting of the following disciplines: physiotherapists representing the KNGF, movement scientists, epidemiologists, a representative of the Dutch multidisciplinary CR guideline committee and a cardiologist representing the CR section of the Dutch Society of Cardiology. An external group, consisting of a clinical exercise physiologist, a physician, and two physiotherapists, reviewed the draft versions of the guideline. The members of the guideline GDG and the external members have declared that they have no conflict of interest. This study was funded by the KNGF.

\section{Clinical and research recommendations}

The CR process is divided into the following phases:

- Clinical phase (phase I)

- Outpatient CR phase (phase II)

- $\quad$ Post-CR phase (Phase III)

This guideline focuses mainly on the outpatient CR phase (phase II).

Table 1 Levels of scientific evidence

\begin{tabular}{|c|c|}
\hline Level of evidence & $\begin{array}{l}\text { Quality levels (intervention } \\
\text { and prevention) }\end{array}$ \\
\hline $\begin{array}{l}\text { Level 1: study at A1 level or at least } \\
\text { two independent A2 level studies }\end{array}$ & $\begin{array}{l}\text { A1 Systematic review of at least } \\
\text { two independent A2 level } \\
\text { studies } \\
\text { A2 Randomised, double-blind, } \\
\text { comparative clinical trial of good } \\
\text { quality and sufficient sample } \\
\text { size }\end{array}$ \\
\hline $\begin{array}{l}\text { Level 2: one study at A2 level or at } \\
\text { least two independent B level } \\
\text { studies }\end{array}$ & $\begin{array}{l}\text { B Comparative study not meeting } \\
\text { all criteria mentioned under A2 } \\
\text { (including case-control studies } \\
\text { and cohort studies) }\end{array}$ \\
\hline Level 3: one B or C level study & C Non-comparative study \\
\hline Level 4: expert opinion ${ }^{\mathrm{a}}$ & $\begin{array}{l}\text { D Opinions of experts, for instance } \\
\text { the members of the guideline } \\
\text { development team }\end{array}$ \\
\hline
\end{tabular}

\footnotetext{
${ }^{\text {a }}$ Additionally, other aspects were used to determine recommendations in this case, such as clinical relevance, safety, patient and professional perspective, availability of devices and resources, health organisations, and ethnical and organisational aspects
} 
Clinical phase (phase I)

It should be noticed that the majority of patients with CHF are referred to $\mathrm{CR}$ straight from the outpatient setting, without recent clinical admission. This subset includes stable patients who remain symptomatic despite optimal medical and device therapy.

Recommendation 1. Stay at intensive care unit (ICU) or coronary care unit (CCU) and mobilisation during the clinical phase (phase I)

Relative rest is recommended during the patients' stay at the CCU after an acute cardiac event or after their stay at the ICU following heart surgery. Dynamic mobilisation exercises and treatment of pulmonary symptoms (if necessary) results in a faster recovery and a better physical health at discharge in CHF patients undergoing revascularisation surgery $[20,21]$ (level 1), valve replacement and (left) ventricular surgery, and after decompensation or other cardiac events (level 4).

Postoperative pulmonary complications (such as obstructive pulmonary diseases) are treated if necessary (as indicated by the pulmonologist or other medical specialist) at the CCU or ICU. Perioperative treatment involves teaching the patient techniques to improve ventilation and to mobilise and cough up sputum (breathing, huffing and coughing techniques) and advising the patient.

The clinical mobilisation should include functional exercises, such as exercises related to activities of daily living (ADL) and walking at an early stage of this phase. Exercise should be discontinued or intensity should be decreased if patients show signs of excessive strain/cardiac overload. The physiotherapist explains the aetiology and/or the treatment (e.g. medication, surgery), ways of coping with $\mathrm{CHF}$ and other complaints during daily life (i.e. how to 'respond to the demands of life', and how to recognise signs of excessive strain), and how to gradually increase the intensity of activities at home. Table 2 lists the referral information provided before the mobilisation starts, signs of excessive strain/ cardiac overload and outcome criteria.

Outpatient CR phase (phase II)

Patients with CHF will be referred to the CR team by their cardiologist when they have returned to a stable state (in terms of filling volume, medication use and functional classification) after a clinical admission or after a routine outpatient check-up. The outpatient CR consists of an intake / assessment procedure, a treatment phase and an evaluation, which will be discussed chronologically in the following sections.

\section{Intake / assessment procedure}

At the start of the outpatient CR phase, all eligible patients should be referred for an intake procedure, carried out by a member of the CR team, in many cases the CR coordinator/ nurse, preferably by using a clinical algorithm for patient needs in CR (Fig. 1) [22].

Based on the results of the assessment procedure, the CR coordinator/nurse, in consultation with the patient, decides what type of care or what interventions are indicated. The patient then goes through a specific assessment for each of the relevant disciplines, after which they start one or more CR programs (Fig. 1.).

If the patient has no contraindications for physical training (Table 3), an additional assessment should be performed by the physiotherapist to define the content of the training program.

The aim of the physiotherapist's assessment is to assess the nature and severity of patients' health problems in relation to their physical functioning (in terms of movements) and to assess the extent to which this can be modified. Fig. 2 shows a flowchart of the assessment procedure.

The assessment focuses on identifying impairments of bodily functions, limitations of activities, restrictions of participation and health problems that may influence the choice of exercise activities to be included in the training program. Limitations of activities may regard their nature, duration and/or quality. The physiotherapist analyses the performance of problematic activities that were identified using the patient-specific complaints instrument. [23] The physiotherapist assesses the quality of the patient's aspects of physical performance (including endurance, strength, speed, agility and coordination) and the degree to which the patient is able to use them. The physical performance during activities perceived as problematical can be scored in terms of duration and intensity, perceived fatigue (Borg Rating of Perceived Exertion (RPE) scale 6-20) [24] and in terms of anxiety, chest pain and dyspnoea (Borg 1-10). If requested by the patient's physician, the physiotherapist can monitor the patient's heart rate and blood pressure during these activities. The modified Shuttle Walk Test (SWT) [25-27] is used to determine patients' functional exercise capacity. The MET method and the Specific Activity Scale (SAS) [28] can be used to estimate whether any discrepancy between the actual performance level and the target level can be eliminated with a suitable training program. The physiotherapist 
Table 2 Referral information and reasons to terminate training during mobilisation, and final outcome criteria (phase I)

\begin{tabular}{|c|c|c|}
\hline Referral information & Reasons to terminate training & Outcome criteria $^{\mathrm{a}}$ \\
\hline Reason for referral & Angina & $\begin{array}{l}\text { Able to function at a sufficient ADL level (including e.g. } \\
\text { walking and self-care, with assistance if necessary) }\end{array}$ \\
\hline Date of hospital admission & $\begin{array}{l}\text { Impaired pump function (shortness of breath } \\
\text { disproportionate to exertion, abnormal fatigue } \\
\text { disproportionate to exertion, increased } \\
\text { peripheral / central oedema) }\end{array}$ & $\begin{array}{l}\text { At least some knowledge of their CHF, and if applicable } \\
\text { about the treatment such as surgery (sternotomy, } \\
\text { wound recovery etc.) }\end{array}$ \\
\hline Diagnosis & $\begin{array}{l}\text { Arrhythmias (high heart rate not in proportion to } \\
\text { exertion, irregular heartbeat, changes in } \\
\text { known arrhythmias) }\end{array}$ & $\begin{array}{l}\text { The patient knows how to cope with their CHF } \\
\text { symptoms and is able to increase exercise intensity } \\
\text { and expand their ADL activities }\end{array}$ \\
\hline Date of event or treatment & Abnormal increase or decrease of blood pressure & \\
\hline Medication use (type and dosage regime) & Fainting & \\
\hline Complications and/ or comorbidities & Dizziness & \\
\hline $\begin{array}{l}\text { Further diagnostic information deemed } \\
\text { relevant by the cardiologist }\end{array}$ & Vegetative reactions (excessive perspiring, pallor) & \\
\hline
\end{tabular}

$A D L$ activities of daily living, $C H F$ chronic heart failure

${ }^{a}$ In some exceptional cases, patients may not have met these goals at the time of discharge from hospital, due to psychosomatic, social or severe physical problems (e.g. comorbidities). These patients may be referred for clinical admission to a specialised multidisciplinary CR centre for more intensive care

measures patients' maximum inspiratory pressure (Pimax) using a Pimax meter. Based on the results of the assessment procedure, rehabilitation goals will be defined.

\section{Treatment phase}

The treatment during the outpatient CR phase comprises three modalities: information/advice, a tailored training program and a relaxation program (Fig. 3). The physiotherapist systematically evaluates the rehabilitation goals, during and at the end of the treatment. Typically, the treatment phase should last for a period 8 to 12 weeks in order to obtain the optimal treatment result.

Information / advice

Information and advice must be given in a multidisciplinary context. The physiotherapist offers the patient assistance (guidance, coaching), information and advice, geared towards their personal goals. Patient education about the disorder and the importance of treatment are required to enable the patient to cope effectively with $\mathrm{CHF}$.

Aims of information and advice may include:

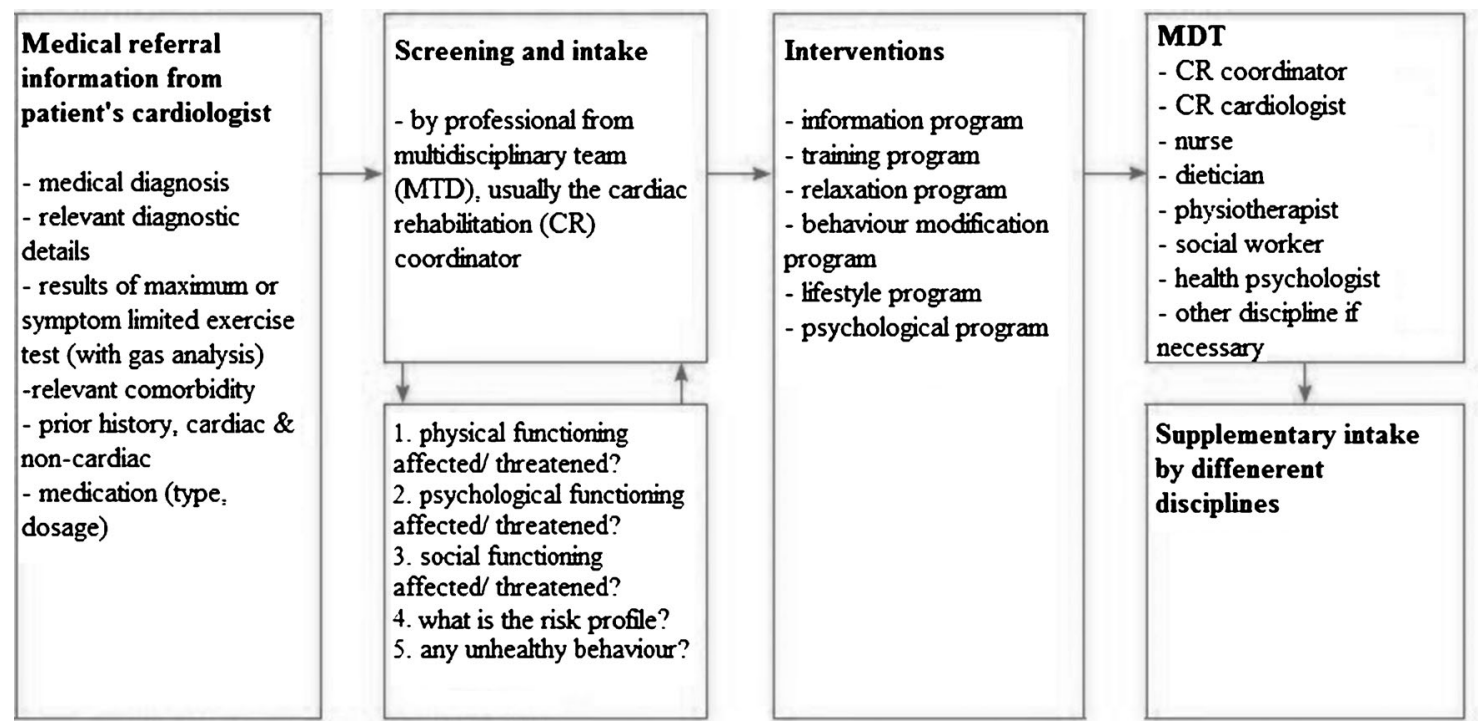

Fig. 1 Flowchart of multidisciplinary cardiac rehabilitation screening 
Table 3 Contraindications for training, signs of excessive strain and safety criteria (phase II)

\begin{tabular}{|c|c|c|}
\hline Contraindications & Excessive strain & Safety criteria \\
\hline $\begin{array}{l}\text { - Progressive increase in heart } \\
\text { failure symptoms } \\
\text { - Severe ischaemia of the cardiac } \\
\text { muscle upon exertion } \\
\text { - Respiratory frequency of more } \\
\text { than } 30 \text { breaths per minute }\end{array}$ & $\begin{array}{l}\text { - Severe fatigue or dyspnoea out of } \\
\text { proportion to the level of exertion } \\
\text { - Angina } \\
\text { - Unexpected increase in breathing rate } \\
\text { (>40 breaths per minute) }\end{array}$ & $\begin{array}{l}\text { - ICD } \\
\text { Cardiologist informs physiotherapist } \\
\text { about safe heart rate range } \\
\text { First } 6-8 \text { weeks after implantation } \\
\text { no (submaximal) strength training } \\
\text { of the upper extremities }\end{array}$ \\
\hline $\begin{array}{l}\text { - Dyspnoea while speaking } \\
\text { - Heart rate at rest }>110 \mathrm{bpm}\end{array}$ & $\begin{array}{l}\text { - Pulse pressure reduction }(\geq 10 \mathrm{mmHg}) \\
\text { - Reduction of systolic blood pressure } \\
\text { during exercise }(>10 \mathrm{mmHg})\end{array}$ & \multirow{2}{*}{$\begin{array}{l}\text { - Diabetes mellitus } \\
\text { Check for wounds and sensory } \\
\text { defects (monofilament test) } \\
\text { Check blood glucose values } \\
\text { before, during and after the exercise } \\
\text { session. Blood glucose values } \leq 5 \\
\text { and } \geq 15 \mathrm{mmol} / \mathrm{L} \\
\text { are relative contraindications for } \\
\text { exercising } \\
\text { Retinopathy of grade } \geq 3 \text { is a relative } \\
\text { contraindication for training }\end{array}$} \\
\hline $\begin{array}{l}\text { - Peak } \mathrm{VO}_{2}<10 \mathrm{~mL} / \mathrm{kg} / \mathrm{min} \\
\text { - Ventricular tachycardia upon } \\
\text { increasing exertion }\end{array}$ & $\begin{array}{l}\text { - Increasing ventricular or } \\
\text { supraventricular arrhythmias } \\
\text { - Vegetative reactions such as } \\
\text { dizziness or nausea }\end{array}$ & \\
\hline $\begin{array}{l}\text { - Poorly controlled diabetes mellitus } \\
\text { (in consultation with patient's } \\
\text { internal medicine specialist) } \\
\text { - Fever } \\
\text { - Acute systemic diseases }\end{array}$ & & $\begin{array}{l}\text { - Pulmonary problems } \\
\text { No desaturation; this usually means } \\
\text { that } \mathrm{O} 2 \text { saturation }(\mathrm{SaO} 2 \text { ) should } \\
\text { remain } \geq 90 \% \text { during exercising } \\
\text { (and should not fall by } \geq 4 \%)^{+}\end{array}$ \\
\hline $\begin{array}{l}\text { - Recent pulmonary embolism } \\
\text { (<3 months ago) causing } \\
\text { severe haemodynamic strain } \\
\text { - Thrombophlebitis }\end{array}$ & & \\
\hline - Acute pericarditis or myocarditis & & \\
\hline $\begin{array}{l}\text { - Haemodynamically serious aortic } \\
\text { stenosis or mitral valve stenosis } \\
\text { - Heart valve failure constituting an } \\
\text { indication for surgical intervention } \\
\text { - Myocardial infarction less than } 3 \\
\text { weeks before the start of the training } \\
\text { - Atrial fibrillation with rapid ventricular } \\
\text { response at rest ( }>100 \mathrm{bpm} \text { ) } \\
\text { - Serious cognitive problems (memory, } \\
\text { attention and concentration) } \\
\text { - Weight gain of }>3 \text { kg within a few } \\
\text { days, whether or not accompanied } \\
\text { by increased dyspnoea at rest }\end{array}$ & & \\
\hline
\end{tabular}

${ }^{a}$ Symmetrical functional movements below the patient's pain threshold (with comfortable rather than forceful movements and controlled breathing) can be started within 6 weeks after surgery (which can also help to prevent the development of a frozen shoulder)

${ }^{+}$The physiotherapist should consult the patient's pulmonologist or cardiologist to decide on the minimum individual saturation value

- Improving patients' understanding of their disorder, CR and illness beliefs;

- Education on a healthy active lifestyle;

- Recognising signs of deterioration (decompensation) of the CHF;

- Promoting compliance;

- Promoting effective ways of dealing with symptoms and exertion in daily life (level of dyspnoea and fatigue);

- Promoting return to work / occupational activities (where applicable, most patients are past retirement age).
Tailored training program

The training program is intended for patients who are:

- Referred by a cardiologist and have no contraindications for training (Table 3);

- Functionally stable (i.e. no change in NYHA class) and on optimal medication for at least 3 weeks;

- $\quad$ NYHA Class II or III; 


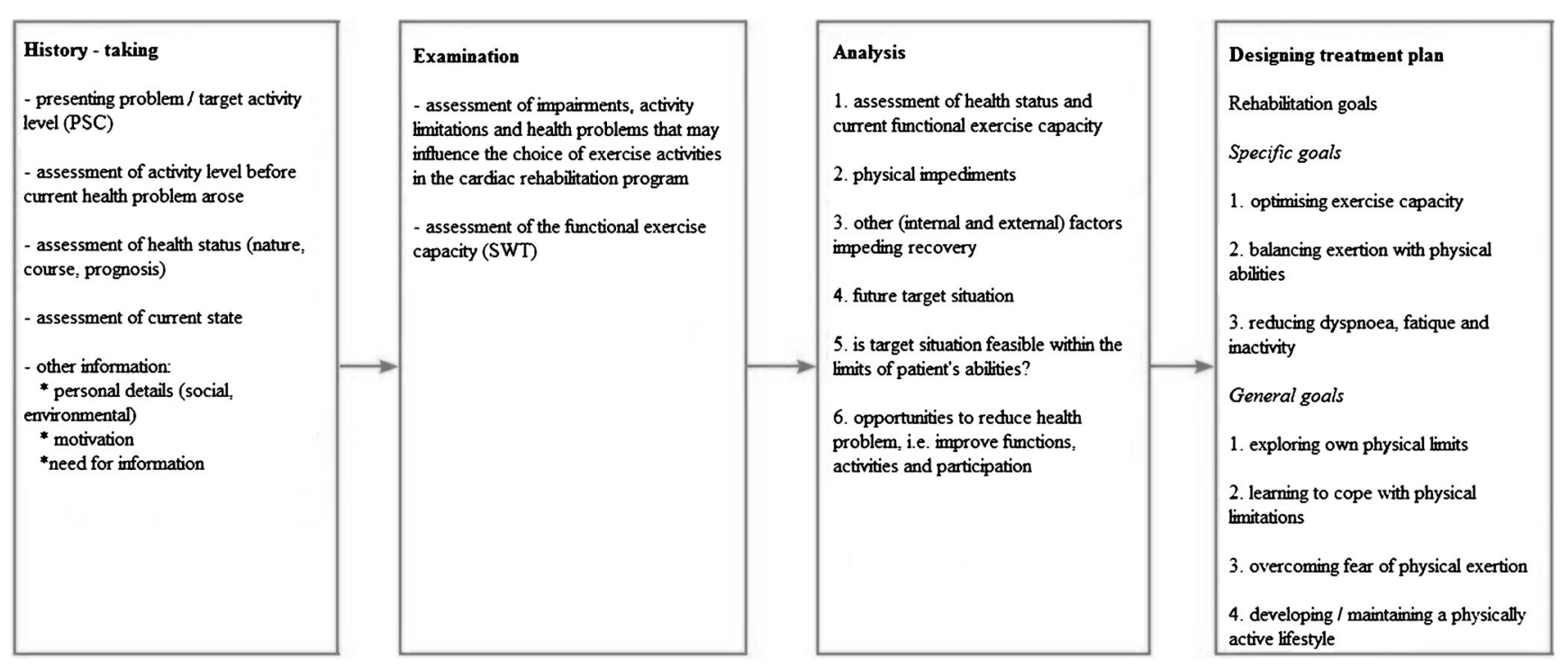

Fig. 2 Flowchart of the assessment procedure performed by the physiotherapist

Based on the individual goals, patients' preferences and limitations established during the assessment procedure in combination with results of the maximum or symptomlimited exercise test with respiratory gas analysis and safety criteria (Table 3), a definite training program is composed. It is important to realise that a substantial number of $\mathrm{CHF}$ patients do not respond to training in terms of an increase in $\mathrm{VO}_{2}$ peak [29, 30].

The physiotherapist observes the patient's training intensity, individual response, tolerance of the exercise load and their overall clinical status. Also the patient's response during the recovery phase after exercise is monitored. The exercise session must be terminated when safety criteria are exceeded, or if there are any reasons for excessive strain (Table 3 ).

During the first 2-4 weeks of the training program, the physiotherapist systematically measures the patient's blood pressure and heart rate (and rhythm) before, during and after the training session. This supervised period is extended if any arrhythmias, ischaemia, angina, blood pressure abnormalities or supraventricular or ventricular ectopy occur during exercising. Patients with documented ischaemia or arrhythmias may need to have their cardiac rhythm monitored by ECG, if indicated by their cardiologist. In the case of comorbidities, the GDG recommends starting the training program, based on the exercise principles, relating to the exercise limiting factor, and/ or the most restrictive pathology or disorder. A low-intensity start is recommended in case of doubt.

The tailored training program may comprise practising skills and activities (to enable patients to utilise their general or strength endurance in motor activities), aerobic interval/ endurance training, strength endurance training (inspiratory muscle training and peripheral muscle training), practising functions/activities, and/or (aerobic) training to reduce cardiovascular risk factors (if atherosclerosis is the underlying case of CHF).

\section{Recommendation 2. Aerobic endurance and/or interval training}

Aerobic endurance or interval training increases the exercise capacity and QoL in patients with CHF (NYHA Classes II-III) and is therefore recommended. The mechanisms underlying these beneficial effects involve improvement of patients' muscle perfusion, muscle metabolism, breathing efficiency, neurohormonal regulation and cardiac pump function (Level 1) [4-6].

It is assumed that high-intensity interval training (HIT) results in a better improvement of left ventricular function than moderate-intensity training (Level 2) [31].

HIT may result in a greater improvement of the aerobic endurance capacity than moderate-intensity training (Level 2) [32].

The research concerning the effectiveness of HIT training is conducted in relatively low-risk CHF patients; therefore the GDG advises to be cautious in patients with a high risk of cardiac overload (Level 4). If HIT is applied, the cardiologist should be informed and safety criteria (Table 3) should be closely adhered to.

Training should be individually directed and functionally geared toward personal goals. If the goal is to improve endurance capacity, aerobic exercise can be gradually increased from 50 to $80 \%$ of $\mathrm{VO}_{2}$ peak/ heart rate reserve, preceded by warming up and followed by cooling down. HIT can involve interval blocks of 4 times $4 \mathrm{~min}$ at $80-90 \%$ of $\mathrm{VO}_{2}$ peak / heart rate reserve, with active recovery for $3 \mathrm{~min}$ at 40 $50 \%$ of $\mathrm{VO}_{2}$ peak / heart rate reserve (as determined by the maximum or symptom-limited exercise test with respiratory 

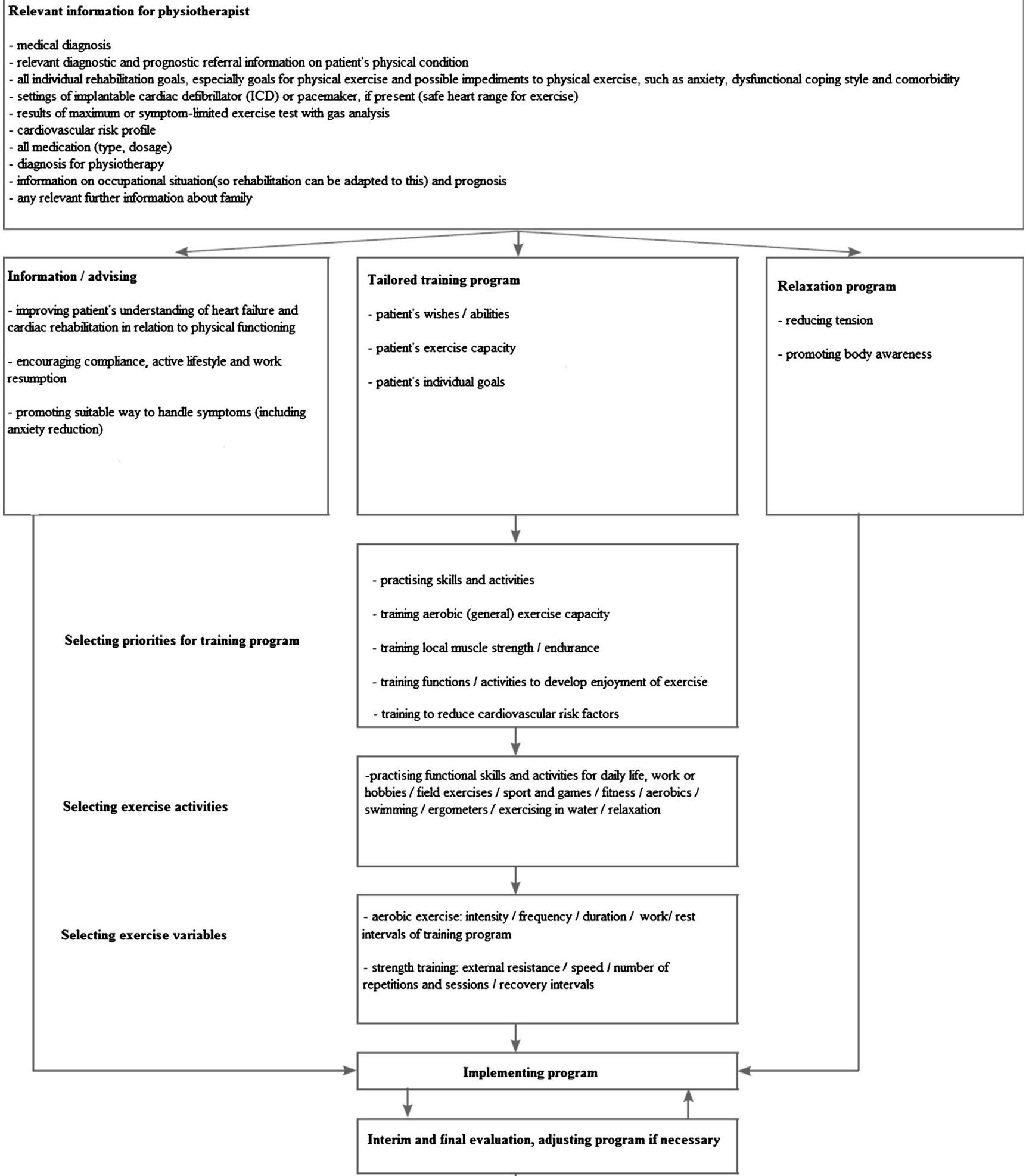

Fig. 3 Flowchart of the physiotherapy process

gas analysis). During both endurance or interval training and HIT, the program should preferably start with a 2-week introductory period in which the patient trains at an intensity of 40
$50 \%$ of $\mathrm{VO}_{2}$ peak / heart rate reserve. Patients with a $\mathrm{VO}_{2}$ peak $>10.5 \mathrm{~mL} / \mathrm{kg} / \mathrm{min}$, but $<17.5 \mathrm{~mL} / \mathrm{kg} / \mathrm{min}$ (3-5 METs $/ 40$ $80 \mathrm{~W})$ appear to benefit most from 1 to 2 training sessions a 
day for $15 \mathrm{~min}$, focusing on aerobic interval training. Patients with a $\mathrm{VO}_{2}$ peak $>17.5 \mathrm{~mL} / \mathrm{kg} / \mathrm{min}(\geq 5$ METs $/ \geq 80 \mathrm{~W})$ can limit their training to 2-3 sessions a week, for 20-30 min per training session [9].

If the goal is to improve patients' endurance capacity, training intensity should be based on the results of a maximum or symptom-limited exercise test with respiratory gas analysis (Table 4), preferably on a percentage of $\mathrm{VO}_{2}$ peak, $\mathrm{VO}_{2}$ reserve (the difference between the $\mathrm{VO}_{2}$ max and the $\mathrm{VO}_{2}$ at rest) or the ventilatory or anaerobic threshold, converted into heart rate (or work rate, Watt). If no respiratory gas analysis has been done, the maximum heart rate attained can be used to calculate the training zone. In both cases, the Karvonen formula is used to calculate the training heart rate as a percentage of the heart rate reserve, added to the resting heart rate. [33] If the patient's heart rate does not rise sufficiently during the maximum or symptom-limited exercise test with respiratory gas analysis, the training intensity should be based on a percentage of the maximum capacity expressed in Power (Watt) or METs, and/or the Borg score (6-20).

Table 4 Information to determine training intensity

- The patient's current physical condition, based on the maximum or symptom-limited exercise test with gas analysis (spiro-ergometry)

- Protocol used

- The referring physician's evaluation of the electrocardiogram before, during and after exercise (criteria for cardiac ischaemia, arrhythmias and the practical consequences of the findings)

- Heart rate at rest, the maximum heart rate and recovery heart rate (especially during the first minute)

- Maximum VO2max and wattage achieved (and the percentage of the predicted value)

- Blood pressure changes at rest, during exercise and during the recovery phase

- The reason for terminating the test and the level of the impairment (central or peripheral)

- Medication use (type and dosage)

- The patient's subjective symptoms during the test (angina/ dyspnoea) and his/her Borg score

- Spiro-ergometry: gas exchange parameters such as maximum oxygen uptake (VO2max), the percentage of predicted VO2max, O2 pulse, maximum respiratory minute volume (VE) (tidal volume and respiratory rate), respiratory exchange rate, anaerobic or ventilatory threshold, VE/VCO2 ratio, saturation and any other relevant parameters (e.g. VO2 oxygen uptake efficiency slope and the presence of respiratory oscillations)

- The maximum voluntary ventilation, which may be derived $(37.5 \times$ the forced expiratory volume (FEV1))

\section{Recommendation 3. Submaximal strength training}

Strength training increases muscle strength and endurance, and is recommended in preparation for, or as an adjunct to, aerobic exercise training for patients with stable CHF (Level 1) [5, 34].

This type of exercise training is particularly suitable for patients who experience strength-related limitations in activities of daily living and during social participation. The GDG advises caution with strength training in the CHF patient (research has only been conducted in relatively low-risk CHF patients), especially in patients with a left ventricular function $<35 \%$ (Level 4 ).

Strength training should be functional and directed toward personal goals and individual restrictions in daily life. The strength training starts with a 2 -week 'pre-training' period, involving 2-3 series of 10 repetitions against a low resistance estimated at $<30 \%$ of 1 repetition maximum (RM). After this pre-training period, the resistance level for strength training can be estimated on the basis of $10 \mathrm{RM}$. If the goal is to improve the patient's muscle strength, the external resistance can be gradually raised from 40 to $65 \%$ of the 1RM. Training the large muscle groups is recommended, at a frequency of 2-3 times a week, in 10-15 repetitions of $2-3$ series.

\section{Recommendation 4. Inspiratory muscle training (IMT)}

IMT increases Pimax and reduces the sensation of dyspnoea and is therefore recommended in CHF patients with a Pimax $<70 \%$ predicted (Level 2) [35-37] or a ventilatory impairment according to the maximum or symptom-limited exercise test with respiratory gas analysis (i.e. insufficient or absent breathing reserve) (Level 4).

Table 5 Situations that may prevail in the final evaluation at the conclusion of the CR program ${ }^{\mathrm{a}}$

- The patient has attained his/her goals at an optimum level

- The patient has partially attained his/her goals, and it seems likely that he/she will be able to continue the training activities elsewhere, under supervision, and thus eventually attain these goals

- The patient has not attained his/her goals and it seems likely that he/she has attained their maximum achievable level. Not all patients will improve their endurance capacity and therefore need for example to spread their energy expenditure and to deal with their dyspnoea in a functional way

a After the outpatient CR phase, all patients with $\mathrm{CHF}$ are referred to aftercare activities (Phase III); in exceptional cases they may be referred to a specialised CR centre for clinical rehabilitation 
High-intensity IMT may produce better results than lowintensity IMT, however in practice the high load training is not suitable for patients with dyspnoea during low ADL effort (Level 4).
Low-intensity IMT should be performed against a resistance of $20-40 \%$ of Pimax for $30 \mathrm{~min} /$ day or 2 times $15 \mathrm{~min} /$ day, on 3-4 days a week, preferably for a period of 8-12 consecutive weeks, and high-intensity IMT against a

Table 6 Evaluation and screening instruments for each goal in physical therapy

\begin{tabular}{|c|c|c|c|}
\hline Goal & Evaluation instrument & When & Final outcome \\
\hline \multicolumn{4}{|l|}{ Specific physical goals } \\
\hline \multirow[t]{2}{*}{$\begin{array}{l}\text { I. Optimising } \\
\text { exercise capacity }\end{array}$} & $\begin{array}{l}\text { By physician } \\
\text { - Maximum or symptom-limited exercise } \\
\text { test with gas analysis plus Borg RPE scale } \\
(6-20) \text {, and as desired scoring Anxiety, } \\
\text { Angina and/or Dyspnoea } \\
\text { By cardiac rehabilitation coordinator } \\
\text { - Subjective physical score on KVL-H } \\
\text { questionnaire }\end{array}$ & $\begin{array}{l}\text { At start and end of CR } \\
\text { and / or training program }\end{array}$ & $\begin{array}{r}\text { Exercise capacity is at optimum } \\
\text { or target level for this patient }\end{array}$ \\
\hline & $\begin{array}{l}\text { By physiotherapist } \\
\text { - As for goals one and two } \\
\text { - (modified) SWT } \\
\text { - Possibly MET method and/or SAS }\end{array}$ & $\begin{array}{l}\text { At start, every } 4 \text { weeks and at end } \\
\text { of CR and/ or training program }\end{array}$ & $\begin{array}{l}\text { Functional exercise capacity is at optimum or } \\
\text { target level }\end{array}$ \\
\hline $\begin{array}{l}\text { II. Balancing exertion } \\
\text { with physical abilities }\end{array}$ & $\begin{array}{l}\text { - Compare subjective exercise capacity } \\
\text { score with objective score } \\
\text { - Ask about five most problematic } \\
\text { activities (PSC) and score these } \\
\text { on the Borg RPE scale (6-20); } \\
\text { possibly score anxiety and/or } \\
\text { angina and/or dyspnoea }\end{array}$ & $\begin{array}{l}\text { At start and end of CR and / or } \\
\text { training program, but also } \\
\text { continuous evaluation to check } \\
\text { for excessive strain }\end{array}$ & $\begin{array}{l}\text { Patient (and partner) coping effectively with } \\
\text { symptoms, that is, patient avoids excessive } \\
\text { strain and (if possible) improves exercise } \\
\text { capacity (goal one). Patient is able to spread } \\
\text { his/her energy expenditure and to deal with } \\
\text { the dyspnoea in a functional way }\end{array}$ \\
\hline $\begin{array}{l}\text { III. Reducing fatigue, } \\
\text { dyspnoea and inactivity }\end{array}$ & $\begin{array}{l}\text { - Borg RPE scale (6-20) for } \\
\text { fatigue and dyspnoea } \\
\text { - Monitor Movement and Health } \\
\text { (www.tno.nl) (in Dutch) }\end{array}$ & $\begin{array}{l}\text { At start and end of } \mathrm{CR} \text { and / or } \\
\text { training program }\end{array}$ & $\begin{array}{l}\text { Patient's sensation of fatigue and dyspnoea is at } \\
\text { optimum or target level. Patient has adopted } \\
\text { a physically active lifestyle }\end{array}$ \\
\hline \multicolumn{4}{|l|}{ General physical goals } \\
\hline $\begin{array}{l}\text { 1. Exploring one's } \\
\text { own physical limits }\end{array}$ & $\begin{array}{l}\text { - Ask for five most problematic } \\
\text { activities (PSC) }\end{array}$ & $\begin{array}{l}\text { At start and end of } \mathrm{CR} \text { and / or } \\
\text { training program }\end{array}$ & $\begin{array}{l}\text { Patient is aware of his/her own physical limits, } \\
\text { i.e. knows what level of exertion is possible }\end{array}$ \\
\hline $\begin{array}{l}\text { 2. Learning to cope } \\
\text { with physical limitations }\end{array}$ & $\begin{array}{l}\text { - Ask patient to carry out problematic } \\
\text { activities and possibly score them for } \\
\text { duration and quality, perceived fatigue } \\
\text { (Borg RPE 6-20) and in terms of anxiety } \\
\text { and / or Angina and / or Dyspnoea } \\
\text { (if indicated). } \\
\text { - Monitoring heart rate and blood } \\
\text { pressure }\end{array}$ & $\begin{array}{l}\text { Monitoring heart rate, measuring } \\
\text { blood pressure and scoring on } \\
\text { Borg scale before, during and } \\
\text { after each session }\end{array}$ & $\begin{array}{l}\text { Patient can cope with physical limitations and } \\
\text { utilise his/her limited energy efficiently, and } \\
\text { has achieved a balance between exertion and } \\
\text { relaxation }\end{array}$ \\
\hline $\begin{array}{l}\text { 3. Overcoming fear } \\
\text { of physical exertion }\end{array}$ & $\begin{array}{l}\text { - History-taking and observation } \\
\text { - Questionnaire: see } \\
\text { Multidisciplinary Guideline CR } \\
2011 \text { (www.nvvc.nl) (in Dutch) }\end{array}$ & $\begin{array}{l}\text { At start and end of } \mathrm{CR} \text { and / or } \\
\text { training program }\end{array}$ & Patient is no longer afraid of exertion \\
\hline $\begin{array}{l}\text { 4. Developing an } \\
\text { active lifestyle }\end{array}$ & $\begin{array}{l}\text { - History-taking (motivational interviewing) } \\
\text { - Monitor Movement and Health } \\
\text { (www.tno.nl) (in Dutch) } \\
\text { - Post-CR activities started }\end{array}$ & $\begin{array}{l}\text { At start and at end of } \mathrm{CR} \text { and / or } \\
\text { training program }\end{array}$ & $\begin{array}{l}\text { Patient has adopted an active lifestyle or is } \\
\text { able to keep up the most active achievable } \\
\text { lifestyle }\end{array}$ \\
\hline \multicolumn{4}{|l|}{ Focal points } \\
\hline $\begin{array}{l}\text { Acquiring information } \\
\text { about secondary } \\
\text { prevention }\end{array}$ & $\begin{array}{l}\text { - Checklist for risk factors / unhealthy behaviour } \\
\text { - Phase III activities started } \\
\text { - Ability to cope effectively with symptoms } \\
\text { - Ability to recognise signs of decompensation }\end{array}$ & $\begin{array}{l}\text { At start and at end of rehabilitation } \\
\text { and / or training program }\end{array}$ & $\begin{array}{l}\text { Patient knows about healthy living and } \\
\text { secondary prevention }\end{array}$ \\
\hline Goals of relaxation program & $\begin{array}{l}\text { - Evaluation list } \\
\text { - Using a flowchart }\end{array}$ & $\begin{array}{l}\text { At interim and final evaluation of } \\
\mathrm{CR} \text { and / or relaxation program }\end{array}$ & $\begin{array}{l}\text { Patient is familiar with the relaxation } \\
\text { program and is able to relax }\end{array}$ \\
\hline
\end{tabular}

Borg RPE scale Borg Rating of Perceived Exertion, $K V L-H$ Dutch quality of life questionnaire for heart patients, $6 M W T$ 6-min walking test, $M E T$ metabolic equivalent of task, PSC Patient-specific complaints, SAS Specific activity scale, SWT Shuttle walk test, CR cardiac rehabilitation 
resistance of $60-70 \%$ of Pimax for 4-5 times 5-10 min/day, 3-4 days a week, preferably 10 consecutive weeks, using a threshold device.

\section{Relaxation program}

\section{Recommendation 5. Relaxation therapy}

A relaxation program (including breathing therapy) is recommended in CHF patients. A relaxation program can lead to tranquillity (a more quiet / less stressful mind), better breathing control (more regular breathing), reduced sensation of dyspnoea and an improvement of QoL (stress reduction) (Level 2) [38-48].

A relaxation program in combination with aerobic training is superior to training alone (Level 3) [40].

The CHF patient should attend two sessions to try out the relaxation program. If the program proves beneficial, they attend a further 6-8 sessions lasting 6090 min each. An important goal of the relaxation program is to teach the patient to calm their mind and to breathe more slowly. In addition, the program may address cognitive themes such as understanding the value of rest, the balance between work and rest, the influence of psychological factors on physical functioning and differentiating between cardiac factors in relation to stress, anger, depression and pressure of time. Instructions for relaxation can be given during exercising (active relaxation) or at rest (passive relaxation), partly in the context of warming up and cooling down, and partly as a separate relaxation program.

\section{Evaluation}

In addition to a 'continuous' evaluation over the entire course of the training program, more comprehensive interim evaluations should be carried out at least every 4 weeks, as well as at the end of the CR program. Final evaluation criteria that may prevail are listed in Table 5.

Table 6 shows the intended outcomes for the CR goals, the relaxation program and patients' acquired knowledge about $\mathrm{CHF}$ and lifestyle, as well as recommendations for assessment and evaluation.

The physiotherapist should report to the multidisciplinary $\mathrm{CR}$ team about the treatment process, the treatment outcomes and the recommendations (aftercare). This should happen at least at the end of the treatment, but preferably also during the treatment period. In addition, the physiotherapist informs the patient's cardiologist, family physician and, if applicable, their rehabilitation physician or company doctor.
Post-CR phase (phase III)

\section{Recommendation 6. Continuation of a physically active lifestyle}

Patients are recommended to continue exercise, as part of an active lifestyle, for the rest of their lives after the outpatient CR period has ended, at a physiotherapy practice, at a certified exercise facility or independently (Level 1-2) [49-51].

Monitoring by secondary care professionals to check if CHF patients maintain their exercise capacity and an active lifestyle in order to identify relapses at an early stage and intervene is advisable (Level 3) [52].

Patients with an indication to attend high-intensity maintenance training ( $\geq 60 \% \mathrm{VO}_{2}$ peak) should be referred to a physiotherapy practice or a certified exercise facility (registered with the Dutch cardiac association), where professional supervision is available. Patients should preferably continue their training activities in a setting that participates in a local network which includes the hospital or rehabilitation centre where the $\mathrm{CR}$ program took place, as this implies easy access and frequent contacts. Patients requiring low- or moderateintensity maintenance training ( $<60 \%$ of $\mathrm{VO}_{2}$ peak) can choose to do this independently, or at a certified exercise facility. If patients who are advised to attend low- to moderate-intensity maintenance training are deemed likely to soon relapse into an inactive lifestyle, they should be referred to a training program at a primary care physiotherapy practice, under professional supervision.

\section{Applicability and implementation issues}

This guideline outlines best practice standards for physiotherapy, in terms of efficacy, efficiency and tailored care, for CHF patients who are eligible for CR. Implementation of the guideline in clinical practice needs further evaluation. [53] Adherence to the guideline needs to be stimulated by, for example, adopting it into a decision supporting system/ flowchart, for example the Dutch clinical algorithm for patient needs in CR [22].

\section{Conclusion}

Strong evidence is found for exercise-based CR in CHF patients, especially for aerobic exercise training (endurance, interval and HIT) during the outpatient rehabilitation, [4-6] and adopting training after supervised CR. [49-51] It can be assumed that treatment of pulmonary symptoms during the stay at the ICU/ $\mathrm{CCU}$ (if necessary) and early mobilisation in the clinical phase (if applicable) leads to a faster recovery, $[20,21]$ and also that strength training, [5, 34] inspiration muscle training (in case 
Pimax $<70 \%$ predicted or when the patient has ventilatory impairment) [35-37] and a relaxation program [38-48] are effective in increasing Qol and exercise capacity, particularly in combination with aerobic exercise training.

This guideline is the first guideline for physiotherapists that provides practical guidance on how to tailor an exercise training program with respect to intensity and duration individually, using results of a maximum or symptom-limited exercise test with respiratory gas analysis. This guideline and also the guideline for exercise-based $\mathrm{CR}$ in patients with coronary artery disease [15] aims to reduce the considerable practice variation which has recently been reported in Dutch CR centres, [7] and thereby, to increase quality of exercise-based CR in the Netherlands [54].

Further research is needed on strategies to improve monitoring and follow-up of the maintenance of a physically active lifestyle after supervised CR; for example by implementing activity monitoring devices combined with telemonitoring, or by web-based coaching platforms to guide patients. [55] Exercise-based CR may also be followed by relatively brief maintenance programs and booster sessions, including behavioural techniques and focusing on incorporating lifestyle changes into daily life, in order to improve long-term adherence to lifestyle modifications. [56] Finally, more research is needed into characteristics and modalities of physical activity and exercise training in CHF in the long term.

Acknowledgments We gratefully acknowledge the contribution of the other members of the GDG: Audrey Merry, Rob Klaver, Sandra Schoonewille, Sandra Verhagen, Harold Leeneman, Judith Verbeek, Shanne Bloemen and Angelique de Rijk, and external reference group: Rob Bertram, Jan van Dixhoorn, Marleen Buruma and Erik Hulzebos. The inclusion of the above persons as reviewers does not imply that each of them agrees with every detail of the Guideline.

Funding This study was funded by the Dutch Royal Society for Physiotherapy (KNGF).

\section{Conflict of interests None declared.}

Open Access This article is distributed under the terms of the Creative Commons Attribution License which permits any use, distribution, and reproduction in any medium, provided the original author(s) and the source are credited.

\section{References}

1. Commission Cardiovascular Prevention and Cardiac Rehabilitation of the Dutch Society for Cardiology. Multidisciplinary guideline heart failure 2011. CBO/NHG/NVVC/NIV and others; 2010.

2. Rutten FH, Poos MJJC, Engelfriet PM. Prevalence of heart failure and mortality rate. [In Dutch] In: Volksgezondheid Toekomst Verkenning, Nationaal Kompas Volksgezondheid; 2014.

3. AHA/ACC guidelines for secondary prevention for patients with coronary and other atherosclerotic vascular disease; 2006.

4. Davies EJ, Moxham T, Rees K, et al. Exercise training for systolic heart failure: Cochrane systematic review and meta-analysis. Eur J Heart Fail. 2010;12:706-15.
5. Bartlo P. Evidence-based application of aerobic and resistance training in patients with congestive heart failure. J Cardpulm Rehabil Prev. 2007;27:368-75.

6. Piepoli MF, Davos C, Francis DP, et al. Exercise training metaanalysis of trials in patients with chronic heart failure (ExTraMATCH). BMJ. 2004;328:189.

7. Vromen T, Spee RF, Kraal JJ, et al. Exercise training programs in Dutch cardiac rehabilitation centres. Neth Heart J. 2013;21:138-43.

8. Balady GJ, Williams MA, Ades PA, et al. Core components of cardiac rehabilitation/secondary prevention programs: 2007 update: a scientific statement from the american heart association exercise, cardiac rehabilitation, and prevention committee, the council on clinical cardiology; the councils on cardiovascular nursing, epidemiology and prevention, and nutrition, physical activity, and metabolism; and the american association of cardiovascular and pulmonary rehabilitation. J Cardpulm Rehabil Prev. 2007;115:2675-82.

9. Commission for Cardiovascular Prevention and Cardiac Rehabilitation of the Dutch Society for Cardiology. Multidisciplinary Guideline for Cardiac Rehabilitation 2011. Utrecht: Dutch Society for Cardiology (NVVC): Rehabilitation commission NVVC and project group PAAHR; 2011.

10. Corra U, Giannuzzi P, Adamopoulos S, et al. Executive summary of the position paper of the working group on cardiac rehabilitation and exercise physiology of the european society of cardiology (ESC): core components of cardiac rehabilitation in chronic heart failure. Eur J Cardiovasc Prev Rehabil. 2005;12:321-5.

11. Giannuzzi P, Saner H, Bjornstad H, et al. Secondary prevention through cardiac rehabilitation: position paper of the working group on cardiac rehabilitation and exercise physiology of the european society of cardiology. Eur Heart J. 2003;24:1273-8.

12. Piepoli MF, Corra U, Benzer W, et al. Secondary prevention through cardiac rehabilitation: from knowledge to implementation. A position paper from the cardiac rehabilitation section of the European association of cardiovascular prevention and rehabilitation. Eur J Cardiovasc Prev Rehabil. 2010;17:1-17.

13. Smith Jr SC, Allen J, Blair SN, et al. AHA/ACC guidelines for secondary prevention for patients with coronary and other atherosclerotic vascular disease: 2006 update: endorsed by the national heart, lung, and blood institute. Circulation. 2006;113:2363-72.

14. Thomas RJ, King M, Lui K, et al. AACVPR/ACC/AHA 2007 performance measures on cardiac rehabilitation for referral to and delivery of cardiac rehabilitation/secondary prevention services endorsed by the american college of chest physicians, american college of sports medicine, american physical therapy association, Canadian association of cardiac rehabilitation, european association for cardiovascular prevention and rehabilitation, inter-american heart foundation, national association of clinical nurse specialists, preventive cardiovascular nurses association, and the society of thoracic surgeons. J Am Coll Cardiol. 2007;50:1400-33.

15. Achttien RJ, Staal JB, van der Voort S, et al. Exercise-based cardiac rehabilitation in patients with coronary heart disease: a practice guideline. Neth Heart J. 2013;21:429-38.

16. van der Wees J, Hendriks H, Heldoorn J et al. Method for development, implementation and revision of guidelines for physiotherapists. Amersfoort/ Maastricht; 2007.

17. Qaseem A, Forland F, Macbeth F, et al. Guidelines international network: toward international standards for clinical practice guidelines. Ann Intern Med. 2012;156:525-31.

18. Commission for Cardiovascular Prevention and Cardiac Rehabilitation of the Dutch Cardiologic Society. Guideline for Cardiac Rehabilitation (DUTCH NVVC);2011.

19. Maher CG, Sherrington C, Herbert RD, et al. Reliability of the PEDro scale for rating quality of randomized controlled trials. Phys Ther. 2003;83:713-21. 
20. Hischhorn AD, Richards D, Mungovan SF, et al. Supervise moderate intensity exercise improves distance walked at hospital discharge following coronary bypass graft surgery - a randomised controlled trial. Heart Lung Circ. 2008; 17:129-38.

21. Mendes RG, Simoes RP, De Souza Melo CF, et al. Short-term supervised inpatient physiotherapy exercise protocol improves cardiac autonomic function after coronary artery bypass graft surgerya randomised controlled trial. Disabil Rehabil. 2010;32:1320-7.

22. Dutch Society for Cardiac Rehabilitation (in Dutch NVVC). Dutch Algorithm for patient needs in Cardiac Rehabilitation (in Dutch "Beslisboom Poliklinische Indicatiestelling Hartrevalidatie") 2012. Utrecht: Hartrevalidatie N-CCCPe, Hartrevalidatie LMDO-H.; 2012.

23. Salén BA, Spangfort EV. Disability rating index. In: Koke AJA, Heuts PHTG, Vlaeyen JS, Weber WEJ. University Hospital Maastricht; 1999.

24. Borg GAV. Psychophysical bases of perceived exertion. Med Sci Sports Exerc. 1982;14:377-91.

25. Keell SD, Chambers JS, Francis DP, et al. Shuttle-walk test to assess chronic heart failure. Lancet. 1998;352:705.

26. Morales FJ, Martinez A, Mendez M, et al. A shuttle walk test for assessment of functional capacity in chronic heart failure. Am Heart J. 1999;138:291-8.

27. Morales FJ, Montemayor T, Martinez A. Shuttle versus 6-min walk test in the prediction of outcome in chronic heart failure. Int J Cardiol. 2000;76:101-5.

28. Goldman L, Hashimoto B, Cook EF, et al. Comparative reproducibility and validity of systems assessing cardiovascular functional class: advantages of a new specific activity scale. Circulation. 1981;64:1227-34

29. Kemps HM, Schep G, de Vries WR, et al. Predicting effects of exercise training in patients with heart failure secondary to ischemic or idiopathic dilated cardiomyopathy. Am J Cardiol. 2008;102:1073-8.

30. Wilson JR, Groves J, Rayos G. Circulatory status and response to cardiac rehabilitation in patients with heart failure. Circulation. 1996;94:1567-72

31. Haykowsky MJ, Liang Y, Pechter D, et al. A meta-analysis of the effect of exercise training on left ventricular remodeling in heart failure patients: the benefit depends on the type of training performed. J Am Coll Cardiol. 2007;49:2329-36.

32. Wisloff U, Stoylen A, Loennechen JP, et al. Superior cardiovascular effect of aerobic interval training versus moderate continuous training in heart failure patients: a randomized study. Circulation. 2007;115: 3086-94.

33. Karvonen MJ, Kentala E, Mustala O. The effects of training on heart rate. Ann Med Exp Biol Fenn. 1957;35:377-81.

34. Spruit MA, Eterman RM, Hellwig V, et al. A systematic review on the effects of moderate-to-high intensity resistance training in patients with chronic heart failure. Heart. 2009;95:1399-408.

35. Dall'Ago P, Chiappa GR, Guths H, et al. Inspiratory muscle training in patients with heart failure and inspiratory muscle weakness: a randomized trial. J Am Coll Cardiol. 2006;47:757-63.

36. Johnson PH, Cowley AJ, Kinnear WJ. A randomized controlled trial of inspiratory muscle training in stable chronic heart failure. Eur Heart J. 1998;19:1249-53.

37. Laoutaris I, Dritsas A, Brown MD, et al. Inspiratory muscle training using an incremental endurance test alleviates dyspnea and improves functional status in patients with chronic heart failure. Eur J Cardiovasc Prev Rehabil. 2004;11:489-96.

38. Chang $\mathrm{BH}$, Hendricks A, Zhao $\mathrm{Y}$, et al. A relaxation response randomized trial on patients with chronic heart failure. J Cardpulm Rehabil. 2005;25:149-57.
39. Curiati JA, Bocchi E, Freire JO, et al. Meditation reduces sympathetic activation and improves the quality of life in elderly patients with optimally treated heart failure: a prospective randomized study. J Altern Complement Med. 2005;11:465-72.

40. Van Dixhoorn J. Relaxation program for patients with heart failure in the Kennemer Gasthuis. Haarlem: Kennemer Gasthuis; 2009.

41. Jayadevappa R, Johnson JC, Bloom BS, et al. Effectiveness of transcendental meditation on functional capacity and quality of life of African Americans with congestive heart failure: a randomized control study. Ethn Dis. 2007;17:72-7.

42. Luskin F, Reitz M, Newell K, et al. A controlled pilot study of stress management training of elderly patients with congestive heart failure. Prev Cardiol. 2002;5:168-72.

43. Parati G, Malfatto G, Boarin S, et al. Device-guided paced breathing in the home setting: effects on exercise capacity, pulmonary and ventricular function in patients with chronic heart failure: a pilot study. Circ Heart Fail. 2008;1:178-83.

44. Pullen PR, Nagamia SH, Mehta PK, et al. Effects of yoga on inflammation and exercise capacity in patients with chronic heart failure. J Card Fail. 2008;14:407-13.

45. Pullen PR, Thompson WR, Benardot D, et al. Benefits of yoga for African American heart failure patients. Med Sci Sports Exerc. 2010;42:651-7.

46. Swanson KS, Gevirtz RN, Brown M, et al. The effect of biofeedback on function in patients with heart failure. Appl Psychophysiol Biofeedback. 2009;34:71-91.

47. Yu DS, Lee DT, Woo J, et al. Non-pharmacological interventions in older people with heart failure: effects of exercise training and relaxation therapy. Gerontology. 2007;53:74-81.

48. Yu DS, Lee DT, Woo J. Effects of relaxation therapy on psychologic distress and symptom status in older Chinese patients with heart failure. J Psychosom Res. 2007;62:427-37.

49. Giannuzzi P, Temporelli PL, Corra U, et al. Antiremodeling effect of long-term exercise training in patients with stable chronic heart failure: results of the exercise in left ventricular dysfunction and chronic heart failure (ELVD-CHF) trial. Circulation. 2003;108:5549.

50. Nilsson BB, Westheim A, Risberg MA. Long-term effects of a group-based high-intensity aerobic interval-training program in patients with chronic heart failure. Am J Cardiol. 2008;102: $1220-4$.

51. Prescott E, Hjardem-Hansen R, Dela F, et al. Effects of a 14-month low-cost maintenance training program in patients with chronic systolic heart failure: a randomized study. Eur J Cardiovasc Prev Rehabil. 2009;16:430-7.

52. Trompers WH, Jongert MWA, Chorus AMJ et al. Web-based monitoring in heart patients (in Dutch). TNO quality of life. 2008.

53. Kemps HM, van Engen-Verheul MM, Kraaijenhagen RA, et al. Improving guideline adherence for cardiac rehabilitation in the Netherlands. Neth Heart J. 2011;19:285-9.

54. Snoek JA, Cramer MJ, Backx FJ. Cardiac rehabilitation: how much pain for the optimal gain? Neth Heart J. 2013;21:135-7.

55. Boyne JJ, Vrijhoef HJ. Implementing telemonitoring in heart failure care: barriers from the perspectives of patients, healthcare professionals and healthcare organizations. Curr Heart Fail Rep. 2013;10: 254-61.

56. Sunamura M, Ter Hoeve N, van den Berg-Emons HJG, et al. OPTImal CArdiac REhabilitation (OPTICARE) following acute coronary syndromes: rationale and design of a randomised, controlled trial to investigate the benefits of expanded educational and behavioural intervention programs. Neth Heart J. 2013;21:324-30. 